\title{
DESARROLLO COGNITIVO Y EDUCACIÓN
}

\author{
Sylvia Sastre, Pilar Bretón, Javier Escorza, $M^{\mathbf{a}}$ Teresa Pascual, \\ Yolanda Soares, Vicente Lázaro y Natalia Merino ${ }^{1}$ \\ Departamento de Ciencias Humanas y Sociales, Universidad de La Rioja
}

Conocer el desarrollo humano es esencial para abordar y dar sentido a la educación en su acepción más amplia dentro de los diversos contextos en los que se realiza. En función de nuestra teoría explicativa del desarrollo, más o menos nativista, constructivista o ambientalista, se derivan las teorías implícitas educativas y prácticas concretas de la intervención educativa en todos los ámbitos de aplicación (formales e informales), en todos los agentes intervinientes (padres, compañeros, educadores), para todos sus componentes (orgánicos, personales, afectivos, cognitivos y de aprendizaje) y durante todo el ciclo vital del individuo en desarrollo.

Ello reclama y justifica el contenido de este monográfico que presentamos, en el que se explicitan alguno de los componentes antes mencionados.

Partiendo de un concepto de desarrollo como proceso de cambio continuado que experimenta un organismo, a lo largo de todo el ciclo vital materializado en distintas etapas o estructuras mentales que se van redescribiendo (desde el período fetal y hasta el fin del ciclo vital, pasando por la pequeña infancia, edad preescolar, edad escolar, adolescencia y adultez o vejez), se deriva que dicho cambio se lleva a cabo a partir de la estrecha y continuada interacción (Plomin y Petrill, 1997) de condicionantes de distinto tipo:

a) orgánicos, entendidos como la base neurobiológica estructural y funcional del cerebro humano como sistema de procesamiento y tratamiento continuado de la información;

b) ambientales, incluyendo en ellos tanto los relativos al entorno físico como social y humano en el que el sujeto está inserto desde su concepción y en cuyo seno se insertan y realizan los actos educativos que le humanizan y/o le particularizan como ser humano.

Estos condicionantes, en estrecha interacción (el orgánico marca la potencialidad, el ambiental: guía, modula y canaliza), dan lugar a distintos cursos de desarrollo ya sea por un mayor ritmo y calidad, ya sea por su menor ritmo y particularidad adquisitiva. Por lo tanto, abogamos por un concepto de desarrollo: neuroconstructivista, interactivo, multimodal, de ciclo vital, recurrente, de cambios cualitativos y cuantitativos.

1. Área de Psicología Evolutiva y de la Educación. Departamento de Ciencias Hunamas y Sociales. C/ Luis de Ulloa, s/n. 26003. Logroño. Correo electrónico: eicur@dchs.unirioja.es 
Finalmente, apresar y conocer explicativa y descriptivamente la naturaleza y características de cada una de las etapas o estructuras mentales que configuran el desarrollo cognitivo, requiere de una metodología que permita apresar la naturaleza de los cambios intraindividuales debidos a factores personales o interindivuales.

Desde este marco, se organizan los distintos artículos que configuran este monográfico, partiendo de la idea de Piaget relativa a que "Una buena Práctica necesita de una buena Teoría" (1954) que sirva siempre de referente orientador y explicativo de las actividades de enseñanza-aprendizaje que formal o informalmente realizamos y que inciden directamente en la guía y modularización sucesiva del desarrollo.

El artículo de la Dra. Marisa Poch nos introduce en las bases neurobiológicas explicativas de la configuración de la arquitectura estructural y funcional del cerebro humano como fundamento orgánico para la sucesiva organización y puesta en funcionamiento de las competencias intelectuales y personales en distintos cursos de desarrollo.

Una de las redefiniciones del concepto de desarrollo cognitivo emergente desde la década de los 60s, proviene de la ampliación del concepto debida a los resultados de las investigaciones neuroconstructivistas centradas en las edades tempranas (fetos, neonatos y primera infancia) y las investigaciones psicológicas de la edad adulta y la vejez. Las consecuencias de dichos resultados han supuesto una revolución en el concepto y explicación del desarrollo, en tanto han ampliado las competencias de los bebés (Mounoud, 1994; Mandler, 1998; Karmiloff-Smith\&Karmiloff-Smith, 1999; etc.) y evidenciando nuevas etapas en la estructura mental durante la adultez y la vejez (Baltes,1997; Schaie,1994;Triadó,2000 etc.) más allá de la perspectiva tradicional del "declive", abogando por la continuada plasticidad y compensación cerebral que permite un buen ejercicio intelectual hasta edades tardías.

Una muestra de los trabajos existentes sobre las "competencias" de los bebés es la conferencia cedida por el Profesor Pierre Mounoud, Catedrático de Psicología del Desarrollo de la Universidad de Ginebra, en la que demuestra que el desarrollo psicológico es el paso del pensamiento a la acción. Posición inversa a la perspectiva piagetiana, que lo considera como el paso de la acción a la representación. Considerando que el desarrollo es, sobre todo, la transformación de los determinantes de nuestra acción, gracias a la construcción de nuevos "puntos de vista", de nuevas representaciones, de nuevas concepciones o teorías, en definitiva, de nuevos sistemas de conocimiento.

Por otra parte, la capacidad intelectual en la vejez y su posibilidad psicoeducativa está plasmada en el trabajo de Carmen Triadó en el que, desde la perspectiva de la Psicología del Ciclo Vital, nos aporta una modificación del concepto tradicional de desarrollo, destacando los cambios que tienen lugar durante la vejez con sus rasgos diferenciales respecto a otras etapas anteriores hacia la consecución del Ilamado "Envejecimiento Satisfactorio" y las posibilidades de adaptación que se ofrecen a nuestros mayores. La visión que aporta es una visión optimista sobre las capacidades intelectuales en la vejez, ya que, dada su plasticidad, existe la posibilidad de que un persona pueda compensar posibles pérdidas para optimizar su desarrollo.

Dado que el curso del desarrollo cognitivo es multimodal, hay que conocer las particularidades de cada alterntiva posible, abordándolos y estudiándolos diferenciamente, tal como se plantea en el trabajo de Sylvia Sastre abarcando el amplio espectro que va desde las altas capacidades hasta el riesgo y las dificultades de desa-rrollo, 
que en ningún caso pueden ser medidas y explicadas, solamente, por comparación con el curso normativo al que la mayoría de instrumentos estandarizados de medida hacen referencia como recurso para orientar las prácticas educativas que se planifican para cada uno de ellos.

La dimensión social del desarrollo se aborda en el artículo de Alfredo Goñi. En él, nos ofrece los resultados de sus investigaciones durante los últimos años sobre la manera en la que se va produciendo el desarrollo del conocimiento sociopersonal, y sobre cómo la intervención educativa puede optimizar dicho proceso.

Coherentemente con lo anunciado al inicio de esta Presentación, se recoge una alternativa metodológica para el estudio y explicación del desarrollo que permite ajustarse a sus particularidades, mediante la Observación Sistemática. El artículo firmado por $M^{a}$ Teresa Anguera, Catedrática de Metodología de las Ciencias del Comportamiento ofrece una completa guía de referencia para el uso de dicha metodología, explicitando tanto los diseños posibles como los pasos y requisitos para la recogida y tratamiento de datos.

En suma, esperamos que este monográfico aporte a investigadores y profesionales de distintas disciplinas que actúan o estudian el desarrollo humano, un panorama sobre la situación actual del concepto y estudio del desarrollo y sus implicaciones educativas derivadas. Así mismo, esperamos que pueda servir como foro de intercambio y discusión entre todos ellos.

\section{Referencias Bibliográficas}

BALTES, P. B. (1997) On the incomplete architecture of human ontogeny. American Psychologist, 52, (366-380)

KARMILOFF-SMITH, K.; KARMILOFF-SMITH, A. (1999). Everything your baby would ask. New York: Golden Books.

MANDLER, J. (1998). Babies Think Before Speech. Human Development, 41(2), 116126.

MOUNOUD, P. (1994). Le passage de répresentations partielles à des répresentations d'ensemble. Enfance, 48 (1), 5-32

PLOMIN, R. y PETRILL, S. A. (1997). Genetics and Intelligence: What's new? Intelligence, 24 (1), 53-78.

SCHAIE, K. W. (1994) The course of adult intellectual development. American Psychologist, 49, 304-313.

TRIADÓ, C.; MARTíNEZ, G. ; VILLAR, F. (2000) Psicología del desenvolupament: adolescència, maduresa $i$ senectut. Barcelona: Edicions Universitat de Barcelona. 